\section{Stop Madagascar's toad invasion now}

Asian common toads

(Duttaphrynus melanostictus)

have begun to invade

Madagascar, threatening the

biodiversity of its unique fauna.

Time is short, so we are issuing

an urgent call to the conservation community and to governments to prevent an ecological disaster.

The first reported sighting of

D. melanostictus on Madagascar was on 26 March in Toamasina.

We collected six adult toads from a swamp in the humid eastern region, six kilometres from Madagascar's largest seaport. More were spotted nearby, suggesting that they arrived from Asia inside shipping containers, as they have elsewhere (see F. Kraus Alien Reptiles and Amphibians; Springer, 2009).

The region provides ideal resources and climate for the toad's spread into the island's interior, and D. melanostictus can range up to an elevation of 1,800 metres. Surveys are now being directed by the biodiversity organization Madagasikara Voakajy to identify the extent of invasion and develop a programme of eradication.

The species poses a significant risk to native fauna, given its life-history characteristics, the evolutionary naivety of the native fauna to toad toxins, and the damage caused in Australia and elsewhere by its relative, the cane toad (Rhinella marina).

Without swift eradication of D. melanostictus, the ecological consequences of an invasion include poisoning and decline of vulnerable native predators (birds, mammals, reptiles), the spread of amphibian diseases, and the secondary effects of food-web disruption. Potential impacts on humans include loss of domestic animals, contamination of drinking water and transmission of parasites in areas with poor sanitation. Jonathan E. Kolby ${ }^{\star}$ James Cook University, Townsville, Queensland, Australia. jonathan.kolby@my.jcu.edu.au ${ }^{*}$ On behalf of 11 co-signatories (see go.nature.com/4ataw3 for full list).

\section{US patient network safeguards data}

Concerns about privacy have led the US National Patient-Centered Clinical Research Network (PCORnet; see go.nature.com/ d9eaee and Nature 508, 432; 2014) to adopt a slightly different approach from the UK National Health Service's care.data programme (see Nature 507, 7; 2014), which has similar goals.

Launched by the PatientCentered Outcomes Research Institute, PCORnet aims to improve patient outcomes by connecting patients, clinicians, researchers and health systems.

PCORnet will not use a centralized database to pool information from multiple networks. Rather, it will leave identifiable patient data behind the firewalls of the 29 participating networks, and distribute programming code that allows the same analysis to be run within each network. In most cases, only aggregated results are transferred for pooling and reporting, which avoids privacy or security risks.

Each PCORnet partner network must engage all its stakeholders in governance. The authority to make final policy decisions on privacy and security and to participate in multi-network studies is vested locally. All research uses of data will be approved and overseen by institutional review boards.

In some cases, individual informed consent will be deemed necessary. In low-risk research, such as observational studies that do not alter treatment choices, networks can favour other forms of communication with patients, especially if obtaining individual consent would render the study unfeasible. Such decisions will also be made locally, and with patient participation.
These measures aim to ensure that PCORnet's 'big data' approach will answer patients' questions about their care while safeguarding the privacy of their personal health information. Joe V. Selby Patient-Centered Outcomes Research Institute, Washington DC, USA.

jvselby@pcori.org

\section{Tackle pollution from solar panels}

There is a downside to China having become the largest producer and consumer of solar energy (J. A. Mathews and H. Tan Nature 508, 319; 2014). The rapidly expanding manufacture of solar photovoltaic products is risking serious environmental pollution.

According to Greenpeace and the Chinese Renewable Energy Industries Association, some two-thirds of the country's solarmanufacturing firms are failing to meet national standards for environmental protection and energy consumption. The production of polysilicon and silicon wafers for solar panels creates dangerous by-products, in particular silicon tetrachloride and hydrofluoric acid, which are being discharged into the environment after inadequate waste treatment (see go.nature. com/mhtayz; in Chinese).

For example, in 2011, fluoride concentrations in the Mujiaqiao River near a solar-panel factory in Haining City, eastern China, were more than ten times higher than permitted, killing fish and raising concerns about human health.

Another source of pollution is the careless disposal of used solar-panel equipment, which includes battery waste containing lead, cadmium, antimony and sulphuric acid (see H. Wang and J. Nima Qinghai Soc. Sci. 5, 58-60; 2007).

Improved waste treatment, environmental monitoring and education are essential to avoid the undesirable impacts of these otherwise valuable technological advances. Hong Yang University of Oslo, Norway.

Xianjin Huang Nanjing

University, China.

Julian R. Thompson University

College London, UK.

hongyanghy@gmail.com

\section{Industries depend on biodiversity too}

Andrew Moss and colleagues lament that raising the public's awareness of biodiversity will not necessarily change behaviour (Nature 508, 186; 2014). A fresh perspective might: the public needs to recognize that biodiversity is crucial to a variety of core industries and not just the province of conservationists.

Biodiversity is not only about vertebrates and flowering plants, as is popularly believed: invertebrates and microbes account for at least $90 \%$ of all species. The genetic, metabolic, physiological and chemical diversity of these species underpins primary industries such as agriculture, grazing, forestry and fisheries.

Many biodiversity elements help to provide crops, timber, seafood and other necessities through ecosystem services. For example, microbes naturally regulate nitrogen and phosphorus in agricultural soils, and wild pollinators increase crop yields. It is therefore ironic that these primary industries so often constitute a threat to biodiversity conservation efforts.

Promoting a popular vision of biodiversity that embraces all kinds of species could lead to conservation being taken more seriously by the public, and by those economic sectors that act as though biodiversity is not important to them.

Andrew J. Beattie Macquarie University, Sydney, New South Wales, Australia.

Paul R. Ehrlich Stanford University, California, USA. andrew.beattie@mq.edu.au 